\title{
Novel Methodology for Arbitration of Talented Students using an Electronic System: A Higher Education Perspective
}

\author{
https://doi.org/10.3991/ijet.v14i21.10916 \\ Asim Seedahmed Ali Osman $\left.{ }^{(}\right)$, Z. Faizal Khan \\ Shaqra University, Shaqraa, Kingdom of Saudi Arabia \\ asalageed@su.edu.sa
}

\begin{abstract}
Arbitration of Talented Students System (ATSS) provides a simple interface for Arbitrator and students to add the talent and evaluate it. It can be used by educational institutes or colleges to evaluate the talented students easily. This methodology depends on ten criteria that are used by arbitrator to evaluate the talent to increasing productivity and efficiency, and also reduce the time and effort in arbitration talent. The proposed methodology allows talented students to follow his talent using a code which is generated automatically by the system. The administrator of the system can accept/reject the talent depending on arbitrator evaluation and his notes. This paper describes all the benefits of the system. It also gives idea about the complete development stages of the system and adapting of the system in the Shaqra University and its impact on the working by developing performance and supporting university in its orientation towards electronic administration.
\end{abstract}

Keywords-Information systems, Talented Students, Shaqra University, Collaboration, Web Based System, Arbitration

\section{Introduction}

Design and implementation of the proposed ATSS and user interface is to reduce paper work and to facilitate and support talent discovery among the students at Shaqra University. Shaqra University is one of the new universities in the kingdom of Saudi Arabia. It's located in the middle of the kingdom and its one of the biggest university in the Arabic gulf region in terms of geographic area. The university has nine branch campuses within the central region of the kingdom. The university consists of twenty four faculties and ten deanships. The colleges are distributed over nine cities, each college and faculty has many departments and units, and any department has many faculty member and employee [1].

This system is proposed in such a way that all the students can use the proposed system to register his talent. They can fill the form which contains information about student and about his talent such as goals, major, type of support he want to improve his talent etc. After these data were saved, the system creates a unique identification 
number which can be used later on to follow or know the status of his registration. The administrator can login to the system using the username/password provided to him. The system allows the administrator to display all talents registered in the system. Then he will assign the talents to an arbitrator depending on major of talent and major of arbitrator. Arbitrators are able to directly access the talents which need arbitration after he enters his username and password. The system displays only assigned talent for the specific arbitrator. The arbitrator evaluates the talent using ten criteria's and the system allows to him to add note about each and every criteria's. Any talent will be evaluated by three arbitrators. The administrator can accept/reject the talent depending on these three arbitrators evaluation.

\section{$2 \quad$ Literature Review}

Talent management (TM) has been considered as a process of human capital management which can be used to measure the activities of individual students [10]. It is a process of attracting the students who can able to do critical tasks in an organization [2], [3]. According to [4], the TM can be categorized according to the two classifications. Initially, it is the process of acquiring the students, training them and finding the individuals who are really talent. It can be a done to make sure the number of talent students in a studying in the classroom. At last, classifying the students based on their level of performance and then providing them with prizes. The TM focuses on various factors such as, management of student's performance, planning of their career and development of their leadership qualities etc.

Authors in [6] did a work on the role of employees and their involvement in the TM process in performance evaluation of an organizational. The TM consists of four factors [7] such as the identification of talent by selecting employees for the positions of leadership in future, planning strategy which enables the talented persons to be prepared for positions in future, development of the talent through education and its consecutive trainings, development of the career. It also focuses on managing the challenging tasks present in job by motivation. Talents can also been measured based on [10]. Using three factors such affective, continuity and commitment. Various software and tools have been proposed by recent researchers for the efficient application of the employee evaluation in order to support the improvement. Various tools such as management of knowledge, management of coordination, information and communication exchange between the employees. An online based task and employee management tool [8] provides various features in order to use it collaboratively. Various features such as notifications panel, calendar panel, comment window, file manager etc. where present in it. It can be used individually or for the teams. All the users who are utilizing it can perform the following operations such as creating sets of checklists, addition of labels, inviting people to join in various tasks and operations, and also connecting with various other applications. 


\section{$3 \quad$ Proposed Methodology}

There are many methodologies which can be used to develop a system. In this proposed methodology we are using an iterative life cycle model shown in figure 1 to develop and implement the application. The main goal of this method is to facilitate the arbitration process of talented students who are studying at Shaqra University. It also reduces the gap between the talented students and talents center. This also provides a simple interface to arbitrate the talents. In this method, we does not start with a full specification of requirements because, in this model the development begins by specifying and implementing just a part of the software which is then reviewed in order to identify further requirements. We started with specific requirements of talented student. The designer and programmer will design, implement, test this version and then it is further given it to the customer side. It is iteratively enhanced throughout the evolving versions until the complete system is implemented and ready to be deployed. Each Iterative model is developed in a specific and fixed time period which is called as iteration. This iteration focuses on a certain set of requirements. Each cycle ends with a usable system i.e., a particular iteration results in an executable release. [5].

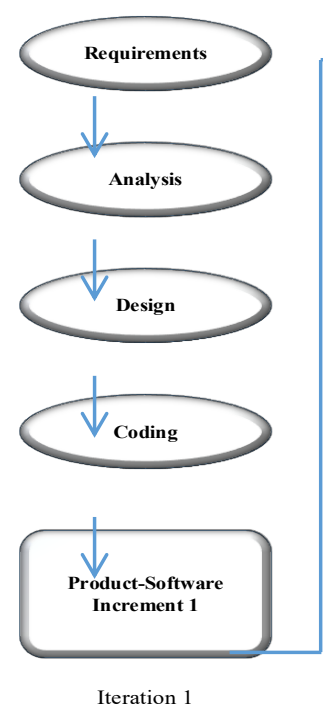

Iteration 1

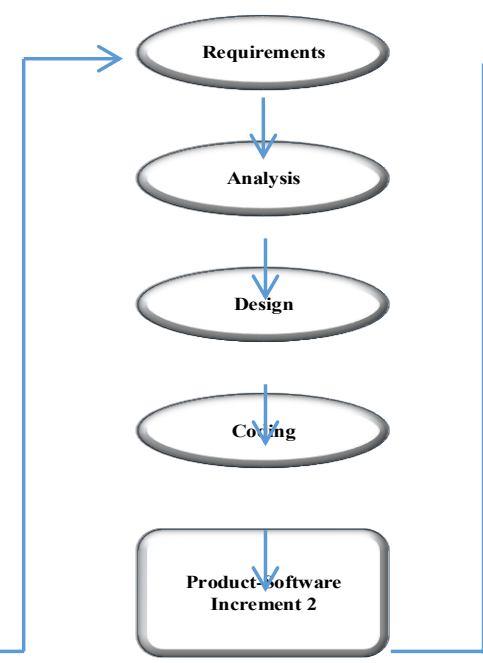

Iteration 2

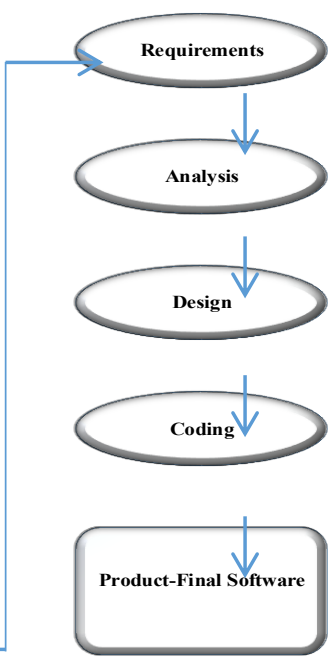

Iteration $n$

Fig. 1. Architecture of the Iterative model used in this methodology

This system is developed to provide three privileges process which is shown in the use case diagram in figure 2 with the various functions for an actor and what he does in it. 


\subsection{Use case diagram}

The use case diagram shown in figure 2 has three actors. First actor is the Administrator of the system who works at talents Center. The Administrator can login into the system and can manage colleges by adding new college, update or delete etc. He can also manage majors, manage arbitrator by adding new arbitrator to the system etc. The Administrator can also send the talent to arbitrator depending on major of talent. Administrator can show many type of reports such as the accepted talents, rejected talents, new talents, show the talents in specific major, show the arbitrator notes and evaluation etc.

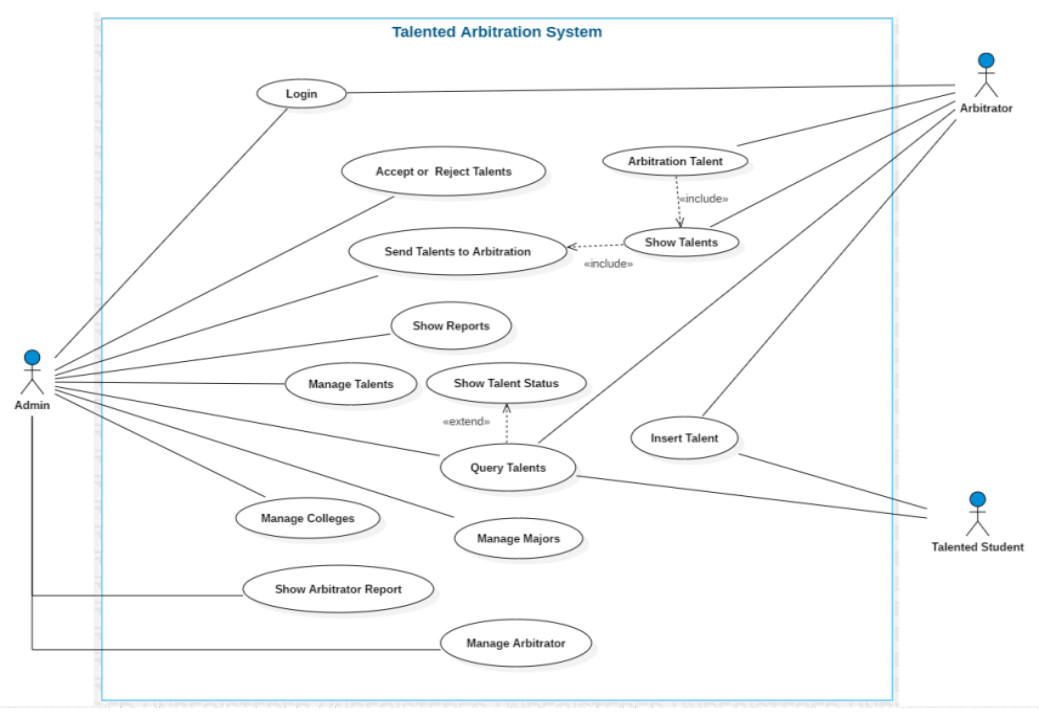

Fig. 2. Use case diagram of the proposed methodology

Second actor is the talented student who can insert his talent into the system and he can query talent using the ID number that's created by the system automatically after he added his talent. He can use this number to display the details of his talent and also to know the status of his talent. The third actor is an arbitrator. Initially he should login to the system. Then, after the login activity, the arbitrator can see the assigned talents in the system, he can evaluate the talents (Arbitration talent) using ten criteria and also, he can add his note to the respective section. The arbitrator can add talent and query talent also.

\section{$4 \quad$ Results and Discussion}

The main interface window of the system is shown in figure 3. It can be used by the administrator and arbitrator to login to access the system and it can also be used by talented student for the process of applying. 


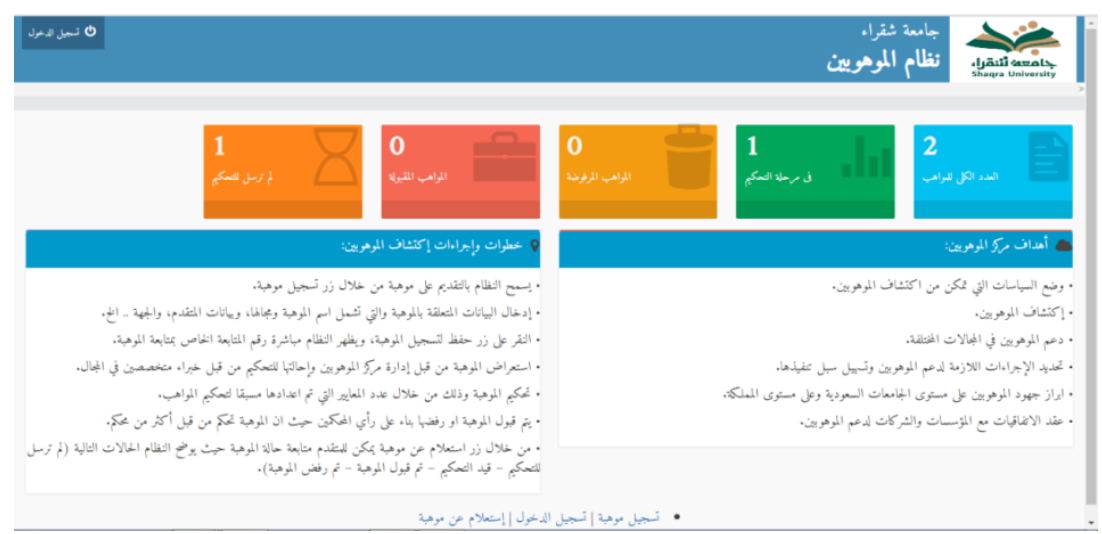

Fig. 3. Main Interface of the proposed arbitration of talented students system

The interface generates statistical report which shows the total number of inserted talents which is shown in blue color. The number of talents under arbitration is shown in green color. The number of rejected talents is shown in orange color. The accepted talent shown in pink color and at last, the talent which is not send yet to arbitration is shown in dark orange in color. This window also includes the information about how to apply and the goals of talents center.

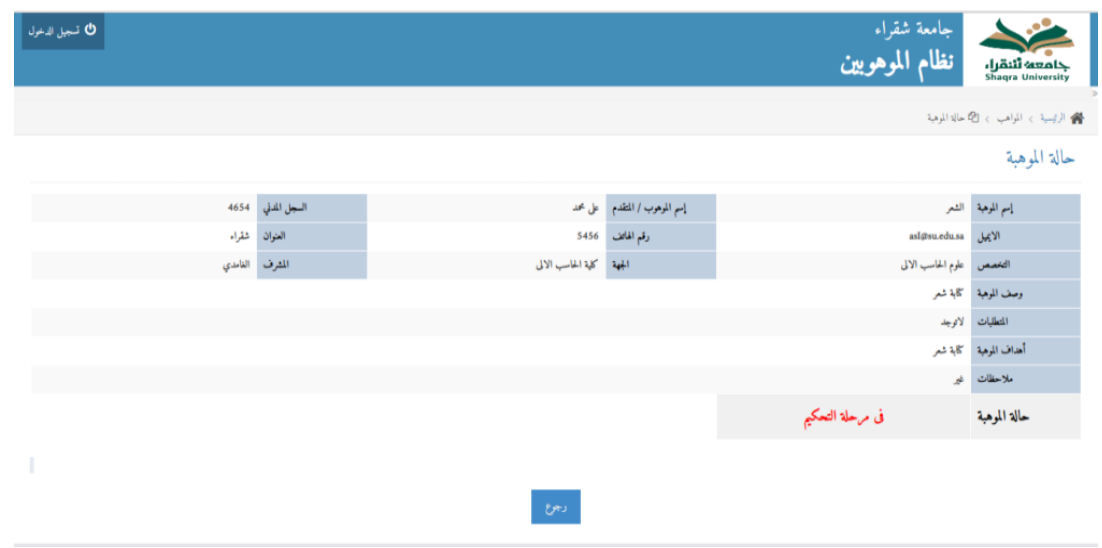

Fig. 4. Talent Query Interface

Figure 4 shows the talent query interface when the talented student inserts his ID number. This window also shows the details such as the name of the talent and name of talented student, major of talent and other details about the talent. The main goal of this report or interface is to show the status of the talent. There are four statuses such as: not send it to arbitration, under arbitration, accepted, rejected. 


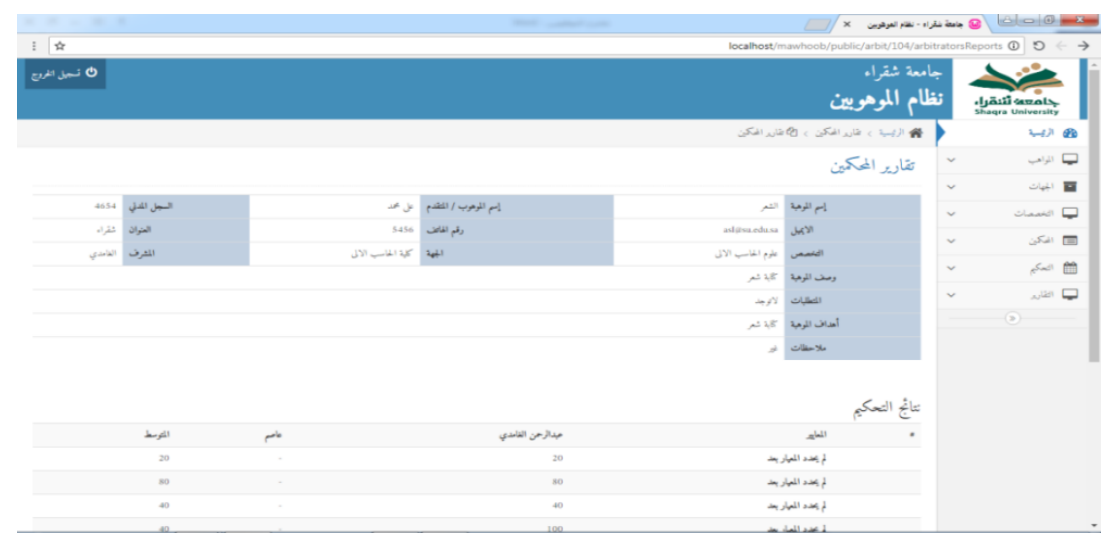

Fig. 5. Arbitrator's evaluation result report

Figure 5 shows the report provided by the proposed system for helping the administrator in order to accept /reject the talents depending on the evaluation of arbitrator. The report shows some information about talents like name of talent, name of talented student, major of the talent, college and other information about talent. Every talent is evaluated by two or three arbitrators. Then, the system calculates the average for every criterion and also calculates the average of summation. This report helps the administrator to decide to accept or reject the talent.

\section{Experimental evaluation (A case study of the Shaqra University)}

\subsection{Data collection}

All the data were collected by interview method by interviewing the four level of the system. This process is done by asking them the following questions:

- Why you need the Arbitration of talented students system

- What is the type of report you need it from the system?

The data collected is shown in table 1 which has the details about the type of users who were involved in the interview and the number of peoples they interviewed.

Table 1. Details about number and types of peoples involved in the interview

\begin{tabular}{|l|c|}
\hline \multicolumn{1}{|c|}{ Type of the user } & Total \\
\hline High level manager (Rector, Consultant of the Rector) & 2 \\
\hline Managers (Dean of the colleges and other Deanships) & 2 \\
\hline Arbitrators (faculty member and staffs) & 15 \\
\hline
\end{tabular}


Table 2 depicts the implementation results for the proposed system. It has the list of arbitration as new talents, talents under arbitration, accepted talents and the rejected talents computed in the proposed system.

Table 2. Implementation results of the proposed system

\begin{tabular}{|l|l|c|}
\hline \multicolumn{1}{|c|}{ SI.No } & \multicolumn{1}{|c|}{ List of arbitration } & Total \\
\hline 1 & New talents & 174 \\
\hline 2 & Talents under arbitration & 442 \\
\hline 3 & Accepted talents & 69 \\
\hline 4 & Rejected Talents & 251 \\
\hline
\end{tabular}

\section{Conclusion and Future Enhancements}

This study proposes a novel methodology of arbitration of talented students in Shaqra University to identify the talented students. This study has aimed to meet the important objectives such as improving competitiveness, increasing talent and efficiency, accelerating knowledge, supporting innovation in the University. A complete idea about the methodology, various stages of the system and an analysis which is used for assuring the adaptability of the system in the Shaqra University is explained. The study has aimed to find the most talented students among all. Using this too improves various student-related activities, monitoring the activities, improving the ability of understanding etc. The results have helped the arbitrator to find the talented students. It also enables the students and their talents in the process of increasing efficiency. Future work can be the proposal of an arbitration tool for collaborating students from various institutions.

\section{$7 \quad$ References}

[1] Asim Seedahmed Ali Osman and Ahmed Seedahmed Ali Osman, Evaluating Employee Performance using Automated Task Management System in Higher Educational Institutions, Indian Journal of Science and Technology, Vol 12(9), March 2019. https://doi.org/ $\underline{10.17485 / \mathrm{ijst} / 2019 / \mathrm{v} 12 \mathrm{i} 9 / 142149}$

[2] Rana, A. and Abbasi, A. (2013). Impact of talent management and employee turnover intention on organizational efficiency: A case of Telecommunication Sector of Pakistan. Science International, 25(3), 637-642.

[3] Al-Lozi, M. S. Almomani, R. Z. Q \& Al-Hawary, S.I.S. (2018). Talent Management strategies as a critical success factor for effectiveness of Human Resources Information Systems in commercial banks working in Jordan. Global Journal of Management and Business Research: A Administration and Management, 18(1), 30-43.

[4] Lewis, R. and Heckman, R. (2006). Talent management: A critical review. Human resource management review, 16(2), 139-154. https://doi.org/10.1016/j.hrmr.2006.03.001

[5] http://www.professionalqa.com/iterative-model.

[6] Devi, S. (2017). Impact of talent management on organizational performance: The role of employee engagement. International Journal of Management Studies, IV (1), 17-27. 
[7] Hughes, J. and Rog, E. (2008). Talent management: A strategy for improving employee recruitment, retention and engagement within hospitality organizations. International Journal of Contemporary Hospitality Management, 20(7), 743-757. https://doi.org/10.1108/09 $\underline{596110810899086}$

[8] Tutty JI, Klein JD. Computer-mediated instruction: A comparison of online and face-toface collaboration. Educational Technology Research and Development. 2008. https://doi. org/10.1007/s11423-008-9092-7

[9] Rees, C., Alfes, K. and Gatenby, M. (2013). Employee voice and engagement: connections and consequences. The International Journal of Human Resource Management, 24(14), 2780-2798. https://doi.org/10.1080/09585192.2013.763843

[10] Kevin Till,Ben L. Jones,Stephen Cobley,et al. Identifying Talent in Youth Sport: A Novel Methodology Using Higher-Dimensional Analysis. Plos One, 2016. https://doi.org/10.137 1/journal.pone. 0155047

[11] Yalcin Vural, Pelin Vardarlier, Abdullah Aykir, The Effects of Using Talent Management With Performance Evaluation System Over Employee Commitment, Procedia - Social and Behavioral Sciences 58 ( 2012 ), pp.340 - 349. https://doi.org/10.1016/j.sbspro.2012.09.10 $\underline{09}$

\section{Authors}

Asim Seedahmed Ali Osman received Ph.D. degree in 2015. He is currently working as an Assistant Professor at the College of Computing and Information Technology, Shaqra University in the Kingdom of Saudi Arabia. His research interests includes opinion mining, sentiment analysis, web based systems.

Z. Faizal khan received Ph.D. degree in 2014. He is currently working as an Assistant Professor at the College of Computing and Information Technology, Shaqra University in the Kingdom of Saudi Arabia. His research interests includes Artificial Intelligence, Intelligent based Systems, Image Processing and pattern Recognition. Currently he is working in a project financed under Shaqra University, grant $\mathrm{Nr}$. D180000/G01/N055.

Article submitted 2019-05-24. Resubmitted 2019-07-23. Final acceptance 2019-07-24. Final version published as submitted by the authors. 